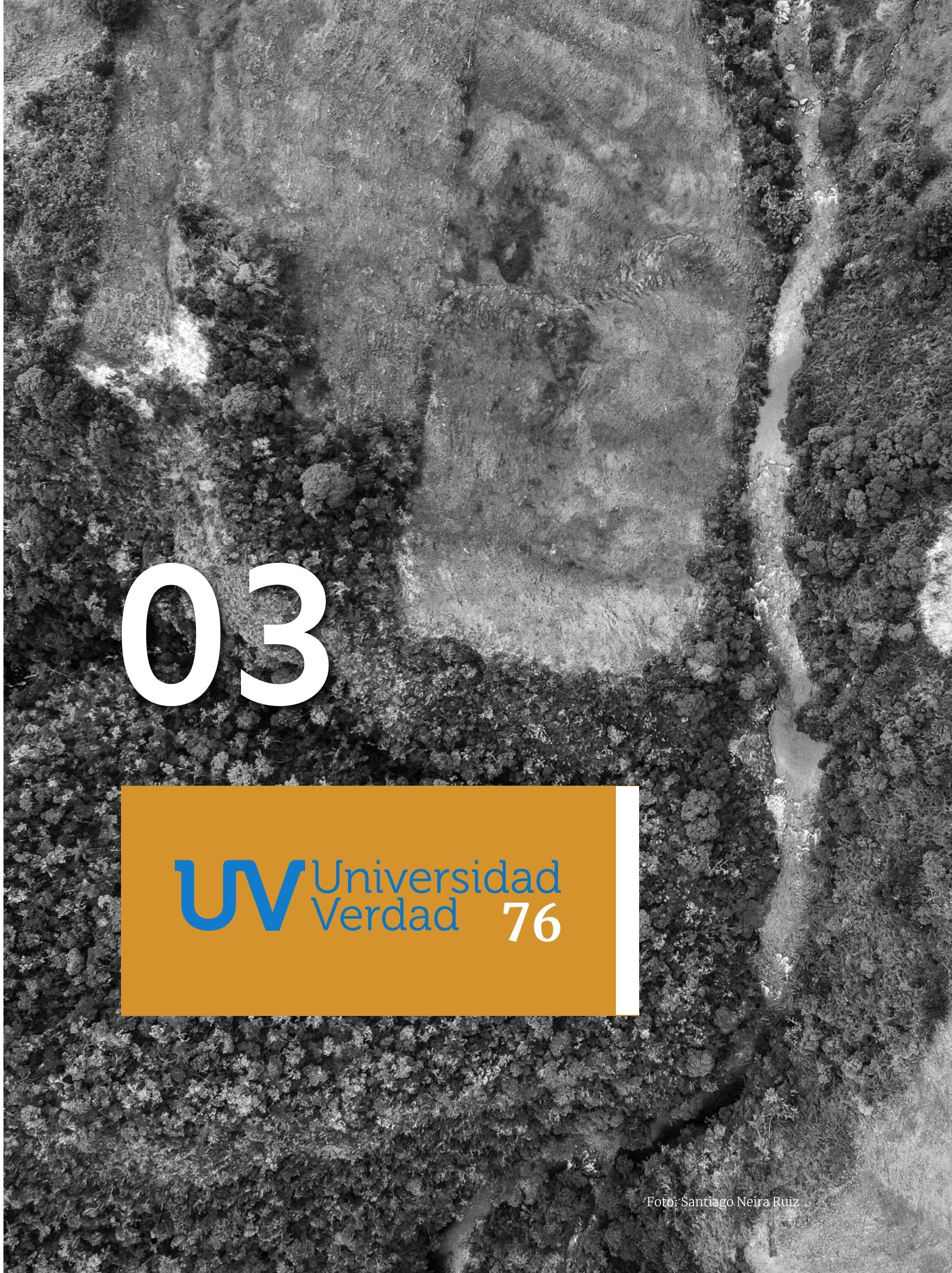




\section{CONCIENCIA Y VISIBILIDAD RETOS A LAS PRÁCTICAS DE GESTIÓN O PRINCIPIOS DEL TURISMO SOSTENIBLE}

\section{Consciousness and visibility Challenges to management practices or principles of sustainable tourism}

(iD) Magíster Martha Raquel Padilla Vargas. Doctoranda en la Facultad de Turismo de la Universidad de La Habana (Cuba) (martha_padilla79@yahoo.es)

(https://orcid.org/0000-0003-0273-9936)

\begin{abstract}
Resumen
El trabajo tiene como objetivo principal esbozar los orígenes de la sostenibilidad, desde sus tres dimensiones, a la vez que nos permite instaurar nuevos retos a las prácticas de gestión, dentro de una actividad turística sostenible y responsable, lo cual genera conciencia y visibilidad, a fin de maximizar los beneficios de la actividad turística dentro de los entornos empresariales, ambientales y socioculturales.
\end{abstract}

Con el propósito de medir el alcance del estudio y sus repercusiones, nos preguntamos: ¿Es posible lograr que el sector sea sostenible y contribuya así al desarrollo económico, el empleo y la reducción de la pobreza, sin destruir la cultura y dañar el ambiente?

En este sentido, sabemos que el turismo es una actividad en permanente evolución, y cuyos procedimientos básicos en torno a la sostenibilidad nos conducen a reflexionar sobre métodos propicios que nos permitan entender a la sostenibilidad como un factor clave para el presente y futuro del desarrollo de la actividad turística; sin embargo, hay que tener en consideración un fenómeno que puede traer conflictos a la hora de llevar a cabo la operación turística; se trata de la masificación de los destinos.
Por ello, dentro de los principales resultados y conclusiones, podemos mencionar que la sostenibilidad puede tener un objetivo vital a largo plazo; no obstante, a la sostenibilidad hay que verla a partir de dos vertientes: una fuerte y otra débil; entendiendo a la sostenibilidad fuerte como aquella cuyo enfoque es ecocentrista; y como débil a aquella cuyo enfoque es tecnocentrista.

\section{Abstract}

The main objective of the work is to outline the origins of sustainability, from its three dimensions, since it allows us to establish new challenges for management practices within a sustainable and responsible tourism activity, which generates awareness and visibility, in order to maximize the benefits of tourism activity within business, environmental and socio-cultural settings.

In order to measure the scope of the study and its repercussions, we ask ourselves: Is it possible to make the sector sustainable and thus contribute to economic development, employment and poverty reduction without destroying culture and damaging the environment? 
In this sense, we know that tourism is an activity in permanent evolution, and whose basic procedures around sustainability lead us to reflect on favorable methods that allow us to understand sustainability as a key factor for the present and future of the development of tourist activity; however, it is necessary to take into consideration a phenomenon that can bring conflicts when carrying out the tourist operation; it is about the massification of

\section{Palabras clave}

Sostenibilidad, Turismo, Gestión.

\section{Keywords}

Sustainability, Tourism, Management. destinations.

Therefore, within the main results and conclusions, we can mention that sustainability can have a vital long-term objective. However, sustainability must be seen from two angles: one strong and the other weak; understanding strong sustainability as one whose focus is ecocentric and weak as one whose focus is technocentric.
1.

\section{Introducción}

Es bien conocido que, en las últimas décadas, se han producido grandes cambios en los ámbitos: económico, político, tecnológico, social y, por supuesto, el turismo no puede escapar a este vertiginoso rumbo. "En 1970 la naciente OMT Organización Mundial del Turismo, estimaba de cierta envergadura 40 países como destinos turísticos. Hoy podemos nombrar más de 140 (Torrejón, 2014, párr. 3)".

No debe entenderse al turismo sostenible como un concepto aislado, más bien se lo debe analizar de forma más amplia e integrada, donde la protección de los recursos naturales debe ser un objetivo de política empresarial. Asimismo, se descubre en la naturaleza un campo para el desarrollo de nuevas actividades turísticas donde el ser humano debe ser respetuoso con el ambiente, y gracias a la toma de conciencia y visibilización, puede significar ahorro de los recursos, buenas y mejores prácticas en torno a la actividad turística, evitando los impactos negativos sobre el ambiente, el paisaje y el medio natural.

Gracias a la conciencia y visibilidad sabemos que todo uso recreativo de la naturaleza modificará. Por más leves que fuesen sus acciones, siempre habrá algún grado de alteración. Es por esta razón que se necesita de una cultura turística que contenga un alto porcentaje de sensibilización social hacia la sostenibilidad, a través de iniciativas y proyectos de desarrollo turístico.

\section{2.}

\section{Materiales y métodos}

El estudio es de carácter teórico. Es decir, aporta elementos al conocimiento científico, con el fin de ampliar la información existente. Para ello, se utilizó el método hipotético-deductivo, que permite la observación del fenómeno y la verificación de la hipótesis. Se procedió a recopilar información basada en los principios de la sostenibilidad turística, con el fin de responder a la interrogante ¿Es posible lograr que 
el sector sea sostenible y que contribuya así al desarrollo económico, al empleo y a la reducción de la pobreza, sin destruir la cultura y dañar el ambiente?

Es preciso considerar que el turismo es un sector muy sensible ante cualquier fenómeno, así, cuando se masifican los destinos, el reto está en lograr armonía entre propios y extraños, con lo cual se establece una estrategia que conduce al desarrollo sostenible. En relación a esto, se localizó y evaluó los retos a las prácticas del turismo sostenible, tomando en consideración que las tres dimensiones de la sostenibilidad merecen un análisis en conjunto, pues las tres se complementan e interactúan, de tal manera que si una de ellas presenta algún obstáculo, impedirá que la actividad turística sea equilibrada y se desarrolle de manera sostenible.

\section{3.}

\section{Orígenes de la sostenibilidad, sus tres dimensiones y el equilibrio entre ellas}

Corría 1972 cuando, gracias al Informe Meadows, surge por vez primera la necesidad de abordar en forma general un crecimiento tomando en cuenta un elemento primordial: la sostenibilidad.

En Costa Rica, se acuñó el término ecoturismo, en 1976, con el fin de limitar el efecto del turismo en los recursos naturales.

Con la celebración de la Comisión Mundial sobre Medio Ambiente y Desarrollo en 1987 o más comúnmente conocido como Informe Bruntland, aparece por primera vez el concepto de "Aquel desarrollo que responde a las necesidades del presente sin comprometer las necesidades de desarrollo y satisfacción de las generaciones futuras" (Visiones del turismo, 2016, párr. 2).

Aplicando este concepto al desarrollo turístico sostenible, tenemos que es: "Aquel que tiene en cuenta las repercusiones económicas, sociales y medio ambientales a la hora de satisfacer las necesidades de los visitantes, de las comunidades anfitrionas y del entorno (Visiones del turismo, 2016, párr. 3).

En España, en 1995, se celebró la Conferencia Mundial sobre Turismo Sostenible y la publicación de la Carta Mundial del Turismo Sostenible. Veinte años después, es decir, en 2015, surge la Carta Mundial de Turismo Sostenible +20 , con lo cual, se establecen acciones que deberán ser tomadas en cuenta en la actividad turística por los gobiernos y organizaciones internacionales, destinos y comunidades locales, turistas, investigadores, redes sociales y organismos sin ánimo de lucro.

El turismo es una actividad eminentemente económica, cuyo efecto sobre la balanza comercial de los países receptores del turismo es positivo; sin embargo, los efectos negativos surgen a partir de la década de los noventa, cuando se evidencia la capacidad de carga o sobre el hecho de poner límites al desarrollo en un determinado territorio. En la Conferencia Mundial de Turismo Sostenible celebrada en 1995 en Lanzarote, se reconoció al turismo como una actividad ambivalente que puede aportar grandes ventajas, pero también contribuir a la degradación ambiental y a la pérdida de la identidad local, por lo que, consideraron, debe ser abordado desde una perspectiva global (Del Valle, 2017).

Nos trasladamos al 2017, que se consolidó como el Año Internacional del Turismo Sostenible para el Desarrollo. Así lo decretó la Organización de $\mathrm{Na}-$ ciones Unidas con el fin de crear conciencia sobre la importancia de lograr un turismo más sostenible, donde participen todos los actores involucrados en el sector y procurar que la actividad turística desarrolle cambios positivos en las sociedades.

En cuanto a las tres dimensiones de la sostenibilidad, estas deben ajustarse a:

1. Ambiente: es imprescindible brindar un óptimo manejo a los recursos medioambientales, procurando su conservación ecológica, diversidad biológica y conservando los recursos naturales, pues estos son insustituibles. 
2. Sociocultural: aunque muchos autores consideran que la cultura sería una cuarta dimensión de la sostenibilidad, nos referimos al acto de respetar la autenticidad de las comunidades anfitrionas, conservar sus valores, costumbres y tradiciones y dar importancia a la tolerancia intercultural.

3. Económico: hace referencia a actividades económicas viables a largo plazo, en la que los beneficios sean distribuidos equitativamente entre las comunidades anfitrionas, y permita la generación de ingresos y servicios sociales que contribuyan a la reducción de la pobreza.

\section{4. \\ Retos a las prácticas de gestión o principios del turismo sostenible}

Los principios del turismo sostenible pueden transformase en prácticas de gestión. Estos principios minimizan los impactos negativos y maximizan los beneficios de la actividad turística en los entornos empresariales, ambientales y socioculturales; por ello, cada vez son más las organizaciones que tratan de articular una gestión turística basada en la sostenibilidad.

Utilizando el turismo como herramienta para el desarrollo sostenible basada en la coordinación público - privada, mencionaremos que el turismo sostenible guarda una estrecha relación, tanto con la realidad social y cultural vinculada a los lugares que el turista visita, como con la experiencia que le brinda la convivencia con las personas autóctonas del destino. Naturalmente, los destinos afrontan cada vez nuevos retos.

Para ello, es importante adoptar retos integradores tales como:

1. Reducir la estacionalidad de la demanda.

2. Abordar el impacto del transporte turístico.

3. Mejorar la calidad de los empleos turísticos.
4. Mantener y mejorar la prosperidad de la comunidad local y su calidad de vida, en el marco del cambio producido.

5. Minimizar el uso de los recursos y la producción de residuos.

6. Conservar y dar valor al patrimonio natural y cultural.

En otras palabras, es preciso reflexionar: ¿Es posible lograr que el sector sea sostenible y contribuya así al desarrollo económico, el empleo y la reducción de la pobreza sin destruir la cultura ni dañar el ambiente? Para responder a esta inquietud se requiere adoptar una estrategia que tenga en cuenta los factores económicos, ambientales, sociales y culturales.

Según la Organización Mundial del Turismo dicha estrategia debe:

a) Hacer un uso óptimo de los recursos ambientales que constituyen un elemento clave en el desarrollo turístico, manteniendo los equilibrios ecológicos esenciales y ayudando a conservar el patrimonio natural y la diversidad biológica.

b) Respetar la autenticidad sociocultural de las comunidades receptoras, conservar su patrimonio cultural vivo y material y sus valores tradicionales, y contribuir a la comprensión intercultural y la tolerancia.

c) Asegurar la existencia de operaciones económicas viables y de largo plazo, procurando la distribución equitativa de los beneficios socioeconómicos entre todos los interesados, lo que incluye el empleo estable, las oportunidades de obtener ingresos y los servicios sociales a las comunidades receptoras, y contribuyendo a la reducción de la pobreza. (Organización Mundial del Turismo, 2013). 
5.

\section{Resultados y discusión}

\subsection{La Sostenibilidad, clave para el futuro de la ac- tividad turística, pero ¡Cuidado con la masificación de los destinos!}

El turismo fue un fenómeno minoritario y centrado principalmente en Europa. Hoy sigue siendo una actividad en constante evolución, pero en los últimos 20 años, la actividad turística se ha disparado por diferentes motivos.

Para García (2009) algunos de esos motivos son:

- El fenómeno de las compañías áreas de bajo coste ha permitido rebajar el precio de los viajes regionales.

- El surgimiento de internet ha generado nuevos canales de comunicación y de venta de productos y servicios turísticos, directamente a los consumidores.

- El crecimiento de las economías emergentes ha generado nuevos flujos turísticos.

- Una mayor oferta de destinos se ha empezado a promocionar internacionalmente para captar turistas.

- Nuevas fórmulas de alojamiento y transportes han distorsionado el mercado y han generado mayores opciones para los turistas.

El crecimiento turístico, así como ha traído ventajas, también ha provocado efectos negativos, principalmente vinculados con los recursos de la población local, "recordemos que la industria turística ha pasado de gestionar 25 millones de turistas en el año 1950, a los más de 1.400 millones que se alcanzaron en el año 2018, con un crecimiento del 6\% sobre el año anterior" (García, 2019, párr. 11).

Al hablar de la masificación de los flujos turísticos, nos referimos al crecimiento exponencial de visitas, principalmente en destinos más tradicionales y que más esfuerzo tienen que desarrollar para lograr una buena convivencia entre los turistas y los ciudadanos locales. De ahí que muchos se cuestionan sobre la sostenibilidad del modelo, pues lograr una convivencia armónica entre turistas y lugareños, muchas veces se torna conflictiva, principalmente por aspectos que tienen que ver con:

- Los ecosistemas locales: Recursos naturales muchas veces amenazados por la llegada de grandes cantidades de gente, a veces en periodos de tiempo muy cortos.

- Aculturación: Gran influencia sobre la cultura local y la calidad de vida de las comunidades receptoras.

- Destinos urbanos transformados y alterados: Con la llegada de turistas al barrio, la vida cotidiana de los locales se transforma. Por ejemplo: suben los precios de las viviendas, productos y servicios, desaparece el comercio tradicional, etc.

Por otra parte, la degradación de los aspectos socioculturales y ambientales, así como el cambio de sistemas productivos y formas de vida de un destino turístico, ha sido un aspecto muy estudiado (OMT, 1999; Mathieson y Wall, 1982; Vera, 1997; Valls, 2003) porque repercute en la calidad y en el éxito o el fracaso de la propia actividad. Y es que el turista no sólo contamina y depreda, en mayor o menor grado, también el crecimiento de la movilidad asociada al turismo es alarmante porque el sitio se degrada, la actividad se destruye y el turista no regresa (Del Valle, 2017).

Dentro del contexto social no sólo se presentan estos conflictos entre la población residente, también se producen intercambios no deseables entre estos y los visitantes, como la aculturación de las comunidades receptoras, la pérdida de la identidad local, del legado cultural y el reemplazo del paisaje cultural por un paisaje artificial que ya no tiene tampoco valor histórico patrimonial (Sánchez, 2011). Esta preocupación se hace más evidente a partir de los años setenta, cuando la visión de la relación entre turismo y territorio se hace más compleja, se alerta sobre la deformación cultural de los destinos y la necesidad de gestionar los comportamientos de los turistas para evitar conflictos con la población residente (Merinero y Pulido, 2009; Almeida y De Souza, 2003). 
Dentro de la sostenibilidad del modelo se hace necesaria la participación de todos los involucrados, sean estos organismos públicos o privados, ciudadanos locales y turistas, que en conjunto tomen conciencia por los impactos económicos, socioculturales y ambientales, "la industria turística representa ya el $10 \%$ de la economía mundial y genera 1 de cada 10 empleos en todo el mundo" (García, 2019, párr. 12).

Gracias a la actividad turística, los contactos que se establecen entre unos pobladores con otros, sus valores, culturas, nivel de ingresos y estilos de vida diferentes, marcan precedentes en un intercambio que puede ser valioso en muchos sentidos; pero tam- bién puede crear fricciones o ser una amenaza para los valores y las culturas establecidas. Algunos observadores sostienen, incluso, que el turismo puede empobrecer la cultura y perturbar a las comunidades del país de destino, perjudicando en particular a las mujeres y a las poblaciones indígenas vulnerables, y puede crear resentimientos y hasta sentimientos de rechazo hacia los turistas extranjeros en los residentes locales (García, 2019).

Es importante mencionar los retos que, basándose en lo planteado por García (2019), presentan los destinos turísticos y la actividad turística; véase la siguiente tabla:

\section{Tabla 1}

Retos para los destinos y turismo

\begin{tabular}{|l|l|l|}
\hline Retos para los destinos & \multicolumn{1}{|c|}{ Recursos } & \multicolumn{1}{|c|}{ Retos para la actividad turística } \\
\hline Gestión del destino & $\begin{array}{l}\text { Recursos naturales, históricos, } \\
\text { culturales }\end{array}$ & $\begin{array}{l}\text { Planificación estratégica a largo plazo, } \\
\text { Gobernanza del destino, } \\
\text { Involucrar a stakeholders, } \\
\text { Ciudadanía }\end{array}$ \\
\hline Cambio climático & $\begin{array}{l}\text { Destrucción de ecosistemas y bio- } \\
\text { diversidad } \\
\text { Inestabilidad meteorológica y su- } \\
\text { bida del nivel del mar }\end{array}$ & Calentamiento global y cambio climático \\
\hline $\begin{array}{l}\text { Reducción de la pobre- } \\
\text { za }\end{array}$ & $\begin{array}{l}\text { Recursos naturales y culturales de } \\
\text { los países en vías de desarrollo que } \\
\text { son un importante recurso econó- } \\
\text { mico }\end{array}$ & $\begin{array}{l}\text { Beneficios del sector turístico se distribuyen de } \\
\text { forma equitativa entre la población local y que los } \\
\text { trabajadores del sector turístico tienen unas con- } \\
\text { diciones de trabajo dignas y justas }\end{array}$ \\
\hline Apoyo a la conservación & $\begin{array}{l}\text { Conservar los recursos naturales } \\
\text { Saltrategia que les permita conservar y mantener } \\
\text { adecuadamente sus recursos naturales y su bio- } \\
\text { diversidad }\end{array}$ \\
\hline Salud seguridad & $\begin{array}{l}\text { El miedo a pandemias sanitarias o } \\
\text { terrorismo afecta a los flujos turís- } \\
\text { ticos }\end{array}$ & $\begin{array}{l}\text { Mayor preocupación mundial en el sector turísti- } \\
\text { co ante diferentes situaciones sanitarias o de falta } \\
\text { de seguridad }\end{array}$ \\
\hline
\end{tabular}




\subsection{Conciencia y visibilidad para un turismo más sostenible}

Para desarrollar conciencia y generar visibilidad en la actividad turística, habrá que generar un turismo que ofrezca ventajas, que piense en aumentar el volumen de visitantes en temporadas más largas y genere nuevos ingresos, de tal manera que "La conciencia turística, se caracterice por una conducta positiva y responsable que necesitamos tener en forma individual y colectiva frente al turismo, esto involucra tanto a los turistas nacionales, como a los extranjeros" (Secretaría Nacional de Turismo de México, 2018).

Esta conciencia que respeta a las personas, a sus costumbres, tradiciones, ambiente y cultura, debe ir de la mano con la hospitalidad, información y seguridad que el viajero espera recibir a la hora de satisfacer su viaje.

En cuanto a la visibilidad de un turismo más sostenible, uno de los retos tiene que ver con la consolidación de la adecuada promoción turística del destino, con campañas publicitarias que atraigan a turistas, que reflejen sus preferencias y gustos dominantes. "Al hablar de sensibilidad o conciencia turística estamos haciendo referencia a la participación de las personas en la búsqueda de mejores condiciones para hacer posible una adecuada calidad en la actividad turística" (Torrejón, 2014, párr.1).

Para el desarrollo de la actividad turística sostenible, se requiere de una participación integral y diversa en torno a las funciones que desempeñamos, ya sea como turistas o anfitriones, en base al perfil de nuestra preparación o de nuestras exigencias; pues al ser el turismo un factor socio-cultural-económico-ambiental requiere de una permanente participación para aportar de manera necesaria a su desarrollo. "Ante la globalización y el desarrollo de los medios de comunicación, el turista nacional e internacional tiene acceso a más y mejor información sobre actividades que podría llevar a cabo, destinos, experiencias y posibilidades de hacer turismo". En ese sentido, hoy más que nunca, la actividad turística demanda alta calidad y un precio competitivo (Torrejón, 2014, párr. 4).
Es por esta razón que la conciencia y visibilidad tienen que ver directamente con otros elementos inherentes al servicio turístico: la calidad y calidez. Asumimos que "la calidad es la vivencia del visitante en relación con su satisfacción plena por los servicios personalizados y eficientes ofrecidos por una comunidad receptora" (Torrejón, 2014, párr. 6). Por ello, cada vez que la competencia se torna agresiva y numerosa, es necesario evaluar los servicios ofertados, pues la calidad marcará la diferencia entre un destino y otro.

De esta manera, la propuesta de calidad que el turista aspira recibir tiene que ver con: preparación, vocación de servicio, actitud frente a obstáculos que pueden presentarse durante la prestación de los servicios, por ello "No hay empresas ni destinos de calidad, sin personas de calidad, y no sólo calidad en términos de profesionalización, sino también de preparación humana que da la coincidencia de sostenida calidad humana" (Torrejón, 2014, párr.8).

Sobre esa misma línea, la noción de trabajar con conciencia y visibilidad en el sector turístico se torna en un factor detonante a la hora de elegir por una determinada empresa, servicio o actividad. Para ello, "hablar de calidad y calidez, se constituye en hacer bien las cosas desde el inicio" (Torrejón, 2014 párr.8). Elegir una empresa en particular, un servicio o una actividad siempre será un detonante porque entran en juego como hemos podido manifestar, varios elementos, entre ellos: la calidad y calidez, para ello es necesario desarrollar una cultura turística y hospitalaria capaz de reflejar lo que pueblos prehispánicos realizaban, es decir, acoger en sus casas a viajeros y abastecerlos de alimentación, pequeños detalles que engrandecen las actividades turísticas, crean conciencia y generan visibilidad en los entornos turísticos. 


\section{Gráfico 1}

Principios básicos de cultura turística

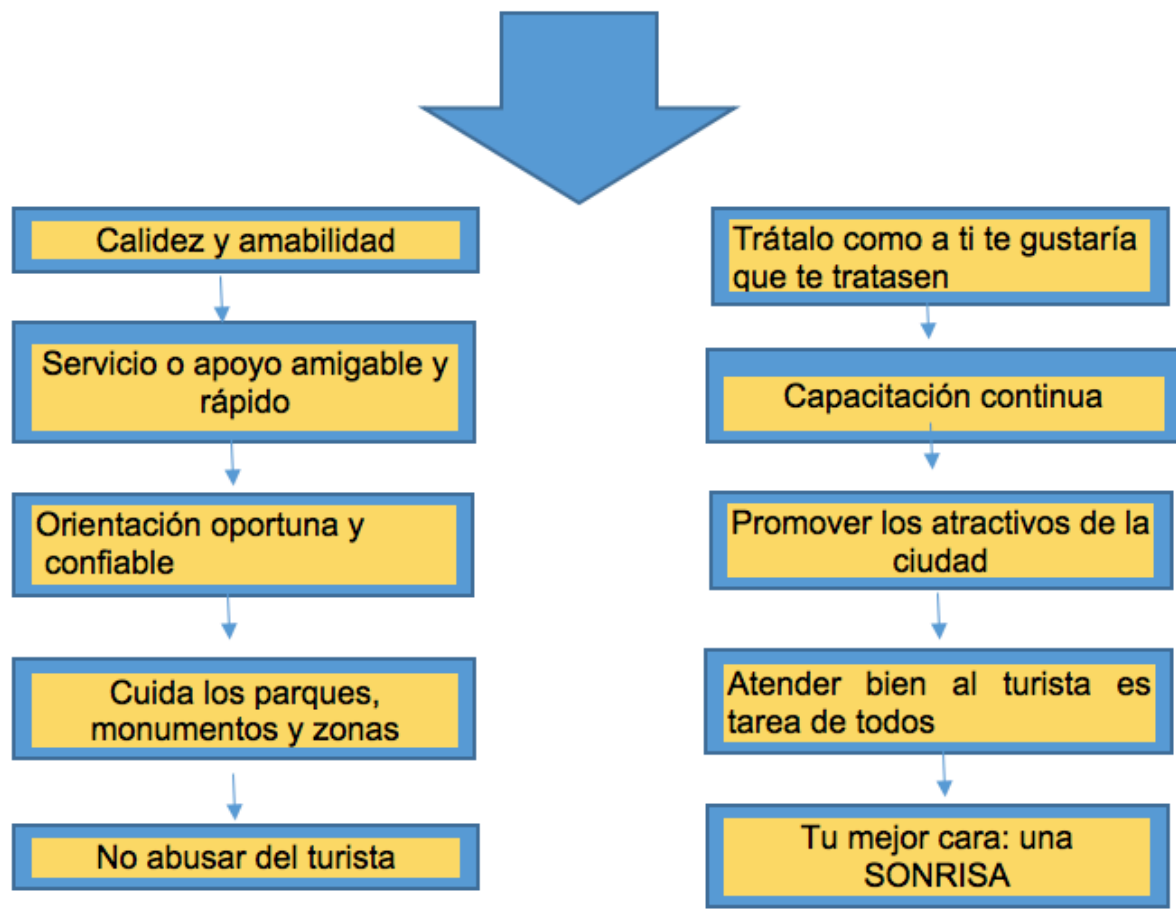

\subsection{Sostenibilidad fuerte vs. sostenibilidad débil}

Es indispensable la existencia de un marco global de cooperación para lograr el desarrollo sostenible, teniendo en cuenta la dimensión económica, sociocultural y ambiental; sin embargo, podemos mencionar un nuevo elemento importante dentro del concepto de desarrollo sostenible: la gobernanza, imprescindible para lograr la consecución del mismo.

Entender la sostenibilidad desde una sola mirada, no es posible, hay que estudiarla desde dos corrientes

\section{Tabla 2}

Sostenibilidad, sus dos vertientes del pensamiento: Sostenibilidad fuerte, cuyo enfoque es ecocentrista; y débil, cuyo enfoque es tecnocéntrico. "La sostenibilidad sigue siendo un objetivo vital a largo plazo, y para alcanzarlo es necesario enverdecer la economía" (Pulido-Fernández, 2015).

\begin{tabular}{|l|l|}
\hline \multicolumn{1}{|c|}{ Sostenibilidad Fuerte } & \multicolumn{1}{c|}{ Sostenibilidad Débil } \\
\hline $\begin{array}{l}\text { Enfoque: ecocentrista = naturaleza tiene valor inherente } \\
\text { en sí misma }\end{array}$ & $\begin{array}{l}\text { Enfoque: tecnocéntrico = el ambiente es uno de los } \\
\text { tipos de capital }\end{array}$ \\
\hline Corriente de pensamiento: Economía ecológica & Corriente de pensamiento: Economía ambiental \\
\hline $\begin{array}{l}\text { Objetivo: Subsistema económico limitado por ecosistema } \\
\text { global y capital natural es insustituible. }\end{array}$ & $\begin{array}{l}\text { Objetivo: Capital se mantenga constante para que fu- } \\
\text { turas generaciones conserven cuotas de utilidad. }\end{array}$ \\
\hline
\end{tabular}


Según Prats (2009), el turismo ha de adaptarse a los cambios y comprometerse con la sostenibilidad. Para ello se exponen ocho razones por las que se entiende que es fundamental la consideración de la sostenibilidad como elemento clave del desarrollo turístico:

\section{Tabla 3}

Elementos de sostenibilidad y sus actividades

\begin{tabular}{|c|c|c|}
\hline \multicolumn{3}{|c|}{ Sostenibilidad elemento clave del desarrollo turístico } \\
\hline \multirow{2}{*}{$\begin{array}{l}\text { Competitividad turís- } \\
\text { tica }\end{array}$} & \multirow{2}{*}{$\begin{array}{l}\text { Gestión basada en la calidad ambiental y } \\
\text { en el desarrollo de un turismo sostenible }\end{array}$} & Modelo de Calgary (Crouch y Ritchie 1999) \\
\hline & & Modelo integrado (Dwyer y Kim 2003) \\
\hline $\begin{array}{l}\text { Consolidación del tu- } \\
\text { rismo como estrategia } \\
\text { de desarrollo endógeno }\end{array}$ & $\begin{array}{l}\text { Gestión de empresas con el objeto de que } \\
\text { éstas sean más ecológicas y, a la larga, } \\
\text { más eficientes }\end{array}$ & $\begin{array}{l}\text { La participación de la comunidad local en } \\
\text { el desarrollo turístico contribuye al desa- } \\
\text { rrollo de la economía local y a la reducción } \\
\text { de la pobreza }\end{array}$ \\
\hline $\begin{array}{l}\text { La reducción de costes } \\
\text { en la industria turística }\end{array}$ & $\begin{array}{l}\text { Tendencia creciente en la industria tu- } \\
\text { rística a invertir en medidas orientadas a } \\
\text { avanzar en la dimensión ambiental de la } \\
\text { sostenibilidad }\end{array}$ & $\begin{array}{l}\text { Transformación ecológica (greening) del } \\
\text { turismo }\end{array}$ \\
\hline \multirow{2}{*}{$\begin{array}{l}\text { Dar respuesta a la ma- } \\
\text { sificación de los flujos } \\
\text { turísticos }\end{array}$} & \multirow{2}{*}{$\begin{array}{l}\text { La congestión causa deficiencias ope- } \\
\text { rativas, genera competencia poco cons- } \\
\text { tructiva por los escasos recursos, conlle- } \\
\text { va un aumento de los costes comerciales } \\
\text { y, en definitiva, una disminución de los } \\
\text { beneficios }\end{array}$} & $\begin{array}{l}\text { i) Control de la congestión en los destinos } \\
\text { turísticos; }\end{array}$ \\
\hline & & $\begin{array}{l}\text { ii) Control de la congestión en los sitios } \\
\text { culturales; y iii) Influencia en la demanda } \\
\text { turística para reducir la congestión }\end{array}$ \\
\hline $\begin{array}{l}\text { Gestión adaptativa de } \\
\text { destinos turísticos }\end{array}$ & $\begin{array}{l}\text { Los destinos no se han planteado con la } \\
\text { rigurosidad suficiente, generar meca- } \\
\text { nismos adecuados de evaluación y con- } \\
\text { trol }\end{array}$ & $\begin{array}{l}\text { Modelo de gestión turística adaptativa } \\
\text { para estos destinos turísticos }\end{array}$ \\
\hline $\begin{array}{l}\text { Reformulación de la } \\
\text { imagen del destino }\end{array}$ & $\begin{array}{l}\text { Apuesta por la sostenibilidad crea una } \\
\text { imagen positiva de cara a la opinión pú- } \\
\text { blica }\end{array}$ & $\begin{array}{l}\text { No sólo es importante cambiar la fiso- } \\
\text { nomía del destino, y aún más su modelo } \\
\text { turístico, sino que hay que comunicar a la } \\
\text { demanda, real y potencial, la nueva filoso- } \\
\text { fía del mismo }\end{array}$ \\
\hline $\begin{array}{l}\text { Consecución de un } \\
\text { nuevo turista }\end{array}$ & $\begin{array}{l}\text { La sostenibilidad es uno de los tres fac- } \\
\text { tores principales a la hora de reservar sus } \\
\text { vacaciones, lo que representa un intere- } \\
\text { sante mercado potencial para los desti- } \\
\text { nos turísticos }\end{array}$ & $\begin{array}{l}\text { Nuevo perfil de turista, más exigente con } \\
\text { el destino en este tipo de cuestiones y más } \\
\text { rentable }\end{array}$ \\
\hline $\begin{array}{l}\text { Garantizar una cultura } \\
\text { de convivencia en los } \\
\text { destinos turísticos }\end{array}$ & $\begin{array}{l}\text { El turismo se ha considerado exclusiva- } \\
\text { mente como un negocio en el que todo } \\
\text { eran aspectos positivos }\end{array}$ & $\begin{array}{l}\text { Aparecen problemas de inflación, satura- } \\
\text { ción de los servicios públicos, inseguridad, } \\
\text { falta de respeto por la identidad cultural de } \\
\text { la sociedad receptora, conflictos por el uso } \\
\text { de los recursos turísticos }\end{array}$ \\
\hline
\end{tabular}


6.

\section{Conclusiones}

Dentro de los entornos económicos, ambientales y socioculturales, el sector turístico contribuye significativamente a reducir la pobreza y llega a ser sostenible cuando se toma en consideración el turismo especializado.

El alcance que tiene la promoción del turismo sostenible y sus repercusiones engloba actividades que van desde la adaptación de nuevas tecnologías y prácticas para mejorar la eficiencia de los sistemas de gestión de energía, agua y desechos, hasta la aplicación de políticas para restablecer la biodiversidad; todo esto en aras de contribuir al desarrollo económico, favorecer las fuentes de empleo y reducir la pobreza, sin dañar la cultura y el ambiente.

Dentro del marco global de cooperación para el logro del desarrollo sostenible, surge la gobernanza como elemento imprescindible para la sostenibilidad a largo plazo. Por lo tanto, consolidar el turismo como una estrategia de desarrollo endógeno, con la participación de la comunidad, permite su propia evolución dentro de la economía local y contribuye a reducir la pobreza.

Entender a la sostenibilidad como un factor clave para el desarrollo de la actividad turística nos conduce a mirar el turismo como una actividad en permanente evolución. Sin embargo en caso de que la gestión de infraestructura, servicios y actividades no gire en torno a las tres dimensiones que se han mencionado, sino conduzca a la masificación de los destinos, puede ser un obstáculo en torno al buen manejo de la operación turística sostenible.

Generar conciencia y visibilidad dentro de la actividad turística permite identificar los encadenamientos relacionados con este sector. Además, puede transformar las prácticas de gestión sostenible, con el fin de: conservar los recursos ecológicos, preservar el patrimonio cultural vivo de las comunidades y procurar la distribución equitativa de los ingresos económicos.

\section{Referencias}

Almeida J. y M. De Souza. (2003) Turismo rural e desenvolvimento sustentá vel: duas experiencias brasileiras. Revista espacio y desarrollo, No. 15. Disponible en: https://bit.ly/3d1C1tE

Crouch, G. I., \& Ritchie, B. J. R. (1999). Tourism, competitiveness, and societal prosperity. Journal of Business Research, 44 (3), 137-152. Disponible en: https://bit.ly/36FgINi

Del Valle, S. (2017). La planificación y prevención de los impactos ambientales del turismo como herramienta para el desarrollo sostenible: Caso de estudio Timotes, Venezuela. Revista Interamericana de Ambiente y Turismo. 13 (2), 164-183 2017. https://bit.ly/2ztSgC8

Dwyer L. and C.W. Kim (2003). Destination Competitiveness and Bilateral Tourism Flows Between Australia and Korea, The Journal of Tourism Studies. 14(2), DEC. Disponible en:

https://bit.ly/2zE2Iaj

García, R. (10 de junio de 2019). La Sostenibilidad, clave para el futuro de la industria turística. Fecha de consulta: 5 de septiembre de 2019.

https://bit.ly/2ZKwyod

Mathieson A. y Wall, G. (1982). Turismo: impactos económicos, físicos y sociales. Editorial Longman, Londres.

Merinero y Pulido (2009). Desarrollo turístico y dinámica relacional. Metodología de análisis para la gestión activa de destinos turísticos. Universidad de Murcia. Revista Cuadernos de Turismo. 23, 173 - 193. Fecha de consulta: 5 de septiembre de 2019. https://bit.ly/3cXCk96 
Organización Mundial del Turismo. (2013). Turismo sostenible: contribución del turismo al crecimiento económico y al desarrollo sostenible. Conferencia de las Naciones Unidas sobre Comercio y Desarrollo. Fecha de consulta: 5 de septiembre de 2019. https://bit.ly/3gxUZLG

Organización Mundial del Turismo. (1999). Guía para administradores locales: desarrollo turístico sostenible, Madrid. Fecha de consulta: 14 de septiembre de 2019. https://bit.ly/30EWfXN

Prats, F. (2009). La evaluación integrada de la sostenibilidad en destinos turísticos. Conferencia Internacional de Turismo. El conocimiento como valor diferencial de los destinos turísticos, Málaga.

Pulido-Fernández, J; Pulido-Fernández, M. (2015). ¿Sigue vigente el paradigma del turismo sostenible? Reflexiones a la luz de la literatura reciente. Universidad de Jaén. Revista Pasos. 13 (6), SpecialIssuePags. 1315-1335. Fecha de consulta: 14 de septiembre de 2019.

https://bit.ly/2MURktF

Sánchez, D. (2011). Indicadores turísticos en la Argentina: Una primera aproximación Consejo Nacional de Investigaciones Científicas y Técnicas (CONICET) Instituto Multidisciplinario de Historia y Ciencias Humanas Departamento de Investigaciones Geográficas. Revista Investigaciones Turísticas. $\mathrm{N}^{\circ} 2$, pp. 29-65. ISSN: 2174 - 5609. Fecha de consulta: 14 de septiembre de 2019.

Secretaría Nacional de Turismo de México (2018). Informe de Gestión 2018, conciencia turística. Turismo accesible. Subdirección de desarrollo. Fecha de consulta: 14 de septiembre de 2019: https://bit.ly/2TPIDVv

Torrejón, A. (03 de noviembre de 2014). ¿Qué es sensibilidad o conciencia turística? Buenos Aires. Pulso turístico. Turismo + Sostenibilidad. Fecha de consulta: 14 de septiembre de 2019: https://bit. ly/2TNQNxx
Valls, J. (2003). Las claves del mercado turístico. Editorial Esade. Barcelona, España.

Vera, J. (1997). Análisis territorial del turismo. Editorial Ariel. Barcelona, España.

Visiones del Turismo. [Blog]. Gestión Sostenible de Destinos Turísticos - Ventajas, retos y objetivos. (20 de septiembre de 2016). Fecha de consulta: 5 de septiembre de 2019. https://bit.ly/2ZK2x80 